\title{
Working
}

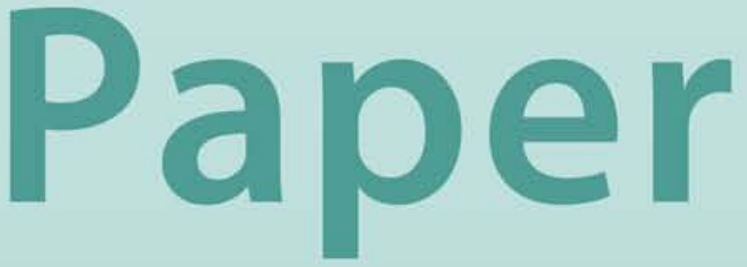




\section{Macro-Hedging for Commodity Exporters}

Eduardo Borensztein, Olivier Jeanne, Damiano Sandri 


\title{
IMF Working Paper
}

\author{
Research Department
}

Macro-Hedging for Commodity Exporters ${ }^{1}$

\section{Prepared by Eduardo Borensztein, Olivier Jeanne, Damiano Sandri}

Authorized for distribution by Gian Maria Milesi-Ferretti

October 2009

\begin{abstract}

\section{This Working Paper should not be reported as representing the views of the IMF.} The views expressed in this Working Paper are those of the author(s) and do not necessarily represent those of the IMF or IMF policy. Working Papers describe research in progress by the author(s) and are published to elicit comments and to further debate.
\end{abstract}

This paper uses a dynamic optimization model to estimate the welfare gains of hedging against commodity price risk for commodity-exporting countries. The introduction of hedging instruments such as futures and options enhances domestic welfare through two channels. First, by reducing export income volatility and allowing for a smoother consumption path. Second, by reducing the country's need to hold foreign assets as precautionary savings (or by improving the country's ability to borrow against future export income). Under plausibly calibrated parameters, the second channel may lead to much larger welfare gains, amounting to several percentage points of annual consumption.

JEL Classification Numbers:C61, E21, F30, F40, G13

Keywords: hedging, commodity exports, precautionary savings, international reserves, futures, options, default

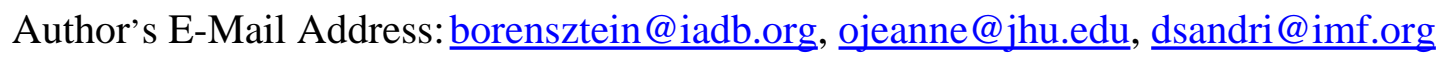

\footnotetext{
${ }^{1}$ We would like to thank seminar participants at a NBER workshop, the Bank of Canada and the International Monetary Fund for useful comments. The views expressed in the paper are those of the authors and do not necessarily represent those of the Inter-American Development Bank or the International Monetary Fund.
} 


\section{Contents}

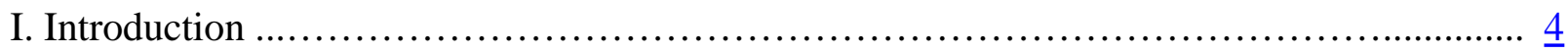

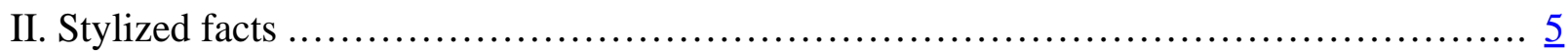

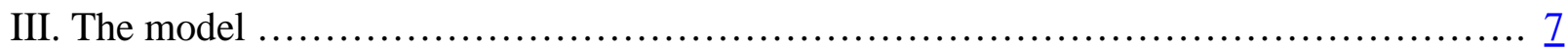

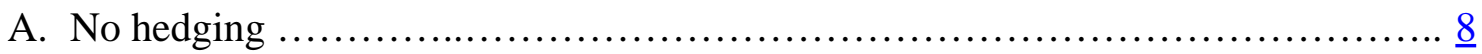

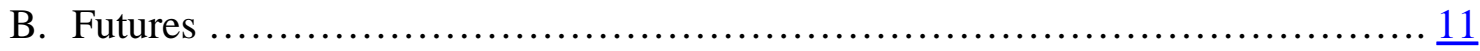

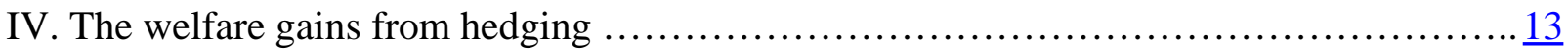

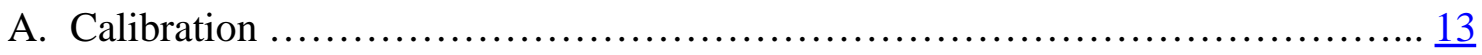

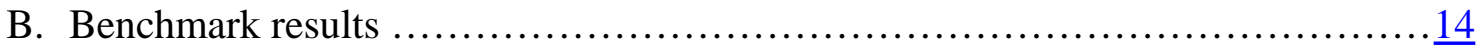

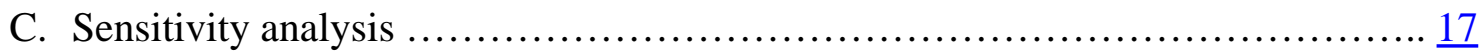

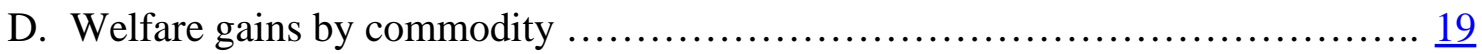

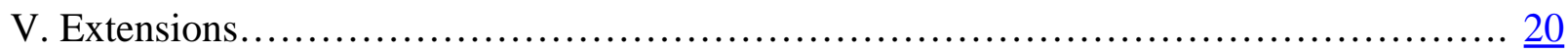

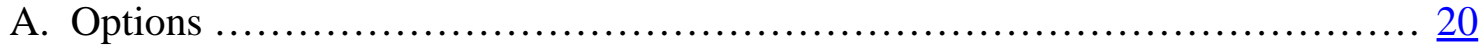

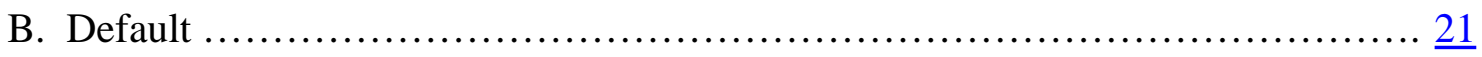

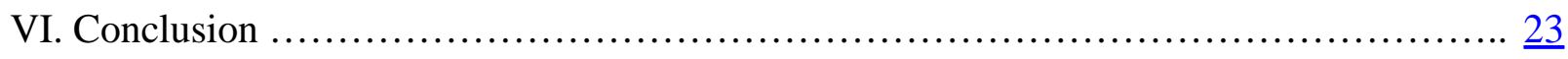

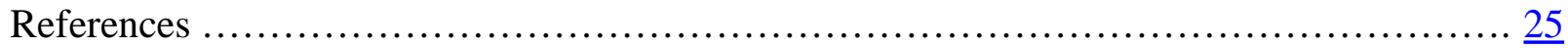

Appendices

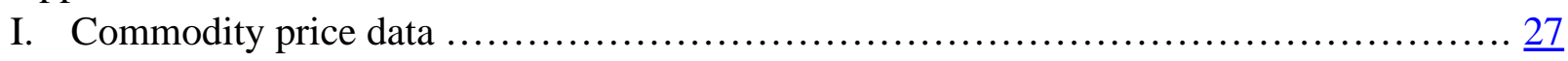

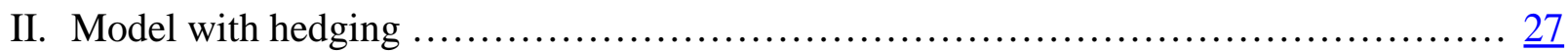

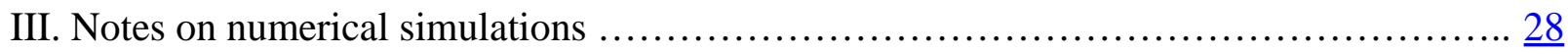

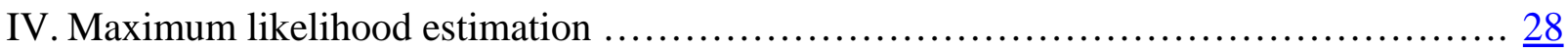

\section{Tables}

1. Countries with 2002-2007 average of commodity net export share of non-commodity-GDP

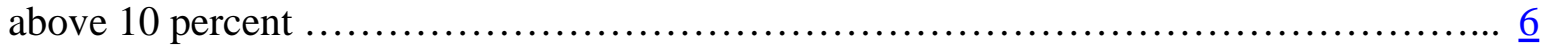

2. Standard deviation of the detrended log of commodity exports and non-commodity GDP $\underline{7}$

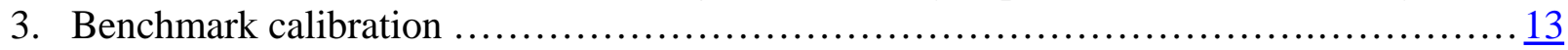

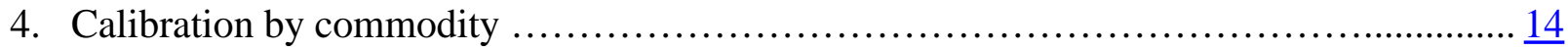

5. Welfare gains from futures by commodity …......................................

6. Commodity price data from International Finance Statistics ........................... $\underline{27}$ 
Figures

1. Average open interest and risk premium (NYMEX July 03 - May 09) ............... $\underline{8}$

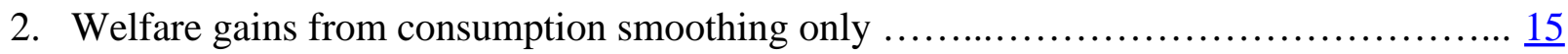

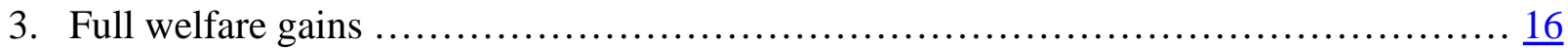

4. Consumption functions and target net foreign asset position ....................... 16

5. Dynamics of net foreign assets and consumption following the introduction of hedging.$\underline{17}$

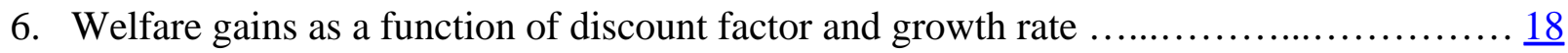

7. Welfare gains as a function of the shock persistency............................... 18

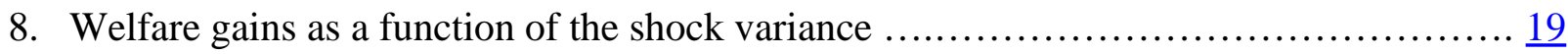

9. Net foreign assets and welfare gains with options and futures contracts ...................... 21

10. Borrowing capacity, equilibrium net foreign assets and welfare gains with defaultable

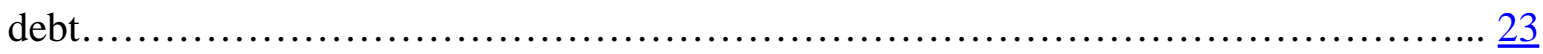




\section{INTRODUCTION}

Commodity exporters can insure against the risk in export income by accumulating foreign assets in commodity stabilization funds, or by hedging with derivative instruments. The first strategy has costs, but reliance on markets for hedging instruments remains limited in spite of the development of those markets in the last two decades. What is the trade-off between precautionary savings and hedging? How is this trade-off affected by the development of markets for hedging instruments? What is the potential welfare gains from further developing those markets?

This paper provides an integrated and welfare-based analysis of those questions based on a dynamic stochastic optimization model. We consider a small open economy with a representative agent that is exposed to risk in the price of the country's commodity exports. The country can insure against this risk by accumulating foreign assets (precautionary savings) or by using hedging instruments that are available at a limited horizon. We characterize the optimal accumulation of foreign assets and hedging policies, and then calibrate the model by reference to data on oil and other key commodities. We measure the welfare gains from using futures and options, and from expanding the horizon of those instruments.

The introduction of hedging instruments enhances domestic welfare through two channels. The first channel, of course, involves income smoothing: reduced income volatility leads to lower consumption volatility and higher welfare if the representative consumer is averse to risk. The welfare gain from this channel should be of the same order of magnitude as the welfare cost of the business cycle, and indeed, we find that it is not very large (although it is larger for developing countries than for advanced economies). For the typical commodity exporter the welfare gain from full insurance coming through this channel amounts to 0.4 percent of annual consumption.

The second channel involves the "external balance sheet" of the economy, i.e., how the country changes its external assets and liabilities when hedging instruments are available. Hedging reduces the need to hold foreign assets as precautionary savings against risk in export income. In addition, hedging allows the country to issue more default-free external debt by reducing the downside risk in export income. We find that the balance sheet channel may yield much larger welfare gains than the income smoothing channel-possibly amounting to several percentage points of annual consumption. The welfare gain from extending the horizon of hedging may also be important, especially if the fluctuations in the price of the commodity are persistent.

We use sensitivity analysis and extensions of the model to better understand the conditions underlying our results. First, a key parameter is the country's "impatience" or willingness to borrow abroad (which is determined by domestic preferences, the growth rate, and the world interest rate). The welfare gains from hedging are large for countries that are impatient and those gains come mainly from the relaxation of the external borrowing constraint. For the other ("patient") countries the welfare cost of maintaining large amounts of precautionary foreign assets is smaller, and so is the benefit of hedging instruments. Second, for the impatient countries most of the welfare gains occur in the first decade following the introduction of new hedging instruments. In the long run domestic consumption is reduced by the service of the debt accumulated in the first decade. Finally, a fraction of the insurance provided by hedging can also be obtained by making external debt defaultable contingent on a low commodity price (although default costs are likely to make this an 
inefficient form of insurance relative to hedging). These caveats complement but do not detract from one basic message of this paper: the welfare gains from hedging come not only from income smoothing but also from improving the country's ability to manage its external balance sheet.

This paper belongs in the literature that applies a precautionary savings framework to analyze a small open economy's optimal accumulation of foreign assets (Ghosh and Ostry (1997); Durdu, Mendoza and Terrones (2009)). More specifically, it belongs in the part of this literature that focuses on risk coming from shocks in the output or price of a commodity export. For example, Arrau and Claessens (1992) apply Deaton (1991) model of precautionary savings to derive the optimal rules for a commodity stabilization fund. Bems and de Carvalho Filho (2009) calibrate a small open economy model to quantify the role of precautionary savings in economies with exhaustible resources. $^{2}$

The main innovation of this paper is to consider precautionary savings jointly with instruments to hedge the commodity price risk. This allows us to estimate the welfare gains from commodity price hedging when precautionary savings provides a realistic alternative. This paper is the first, to our knowledge, to provide such estimates in a stochastic dynamic optimization model of a commodity-exporting country. Caballero and Panageas (2008) show, in the context of a dynamic general equilibrium model, how optimal hedging strategies can help a country to save on precautionary savings against sudden stops in capital flows.

The paper is structured as follows. Section II presents some stylized facts about commodity exports as a source of volatility and about reliance on hedging instruments. Section III presents the model. Section IV presents our calibration of the model as well as our estimates of the welfare gains from hedging. Section V presents two extensions of the basic framework and section VI concludes.

\section{Stylized FACTS}

A substantial number of developing countries heavily depend on the export of one single commodity. This is especially true for Petroleum, which is by far the most internationally traded commodity, but also for Copper, Gold and Natural Gas. Table 1 lists those countries with an average ratio of commodity net export $(X)$ to non-commodity GDP $(Y)$ between 2002 and 2007 of at least 10 percent. $^{3}$ We identify more than 40 cases, with ratios that in the case of Petroleum often exceed 30 percent and exceed 80 percent for Saudi Arabia.

This heavy dependence on commodity exports can cause substantial undesirable volatility in the economy. Table 2 shows that the standard deviation of commodity export income, $\sigma(\tilde{X})$, tends to be more than twice as large as that of non-commodity income, $\sigma(\tilde{Y}){ }^{4}$

\footnotetext{
${ }^{2}$ See also Engel and Valdés (2000) and our companion paper Jeanne and Sandri (2009) .

${ }^{3}$ Commodity export data are from UN COMTRADE retrieved though World Integrated Trade Solution (WITS). We use the IMF Commodity Unit product aggregates based on the SITC3 classification. GDP data are from the World Bank World Development Indicators database. We consider countries with at least 3 data points over 2002-2007.

${ }^{4}$ Standard deviations are computed with data from the countries listed in Table 1, starting from the first year at which
} 
Table 1. Countries with 2002-2007 average of commodity net export share of non-commodity-GDP above 10 percent

\begin{tabular}{|c|c|c|c|c|c|}
\hline Commodity & Country & $X / Y(\%)$ & Commodity & Country & $X / Y(\%)$ \\
\hline \multirow{3}{*}{ Aluminum } & Mozambique & 18.3 & \multirow{21}{*}{ Petroleum } & Saudi Arabia & 81.5 \\
\hline & Guinea & 15.6 & & Kuwait & 73.2 \\
\hline & Jamaica & 11.2 & & Gabon & 63.8 \\
\hline \multirow{2}{*}{ Cocoa } & $\overline{\text { Cote }} \overline{\mathrm{d}}$ 'Ivoire & 16.6 & & Oman & 63.2 \\
\hline & Ghana & 10.7 & & Brunei & 55.8 \\
\hline \multirow{4}{*}{ Copper } & $\bar{Z}^{-} \overline{a m b}^{-}$ & $2 \overline{3} . \overline{4}$ & & United Arab Emirates & 54.1 \\
\hline & Mongolia & 19.1 & & Nigeria & 48.2 \\
\hline & Chile & 19.0 & & Qatar & 40.9 \\
\hline & Papua New Guinea & 11.4 & & Venezuela & 37.9 \\
\hline \multirow{2}{*}{ Fish } & Iceland & $1 \overline{0.4}$ & & Azerbaijan & 36.6 \\
\hline & Maldives & 10.3 & & Bahrain & 34.8 \\
\hline \multirow{5}{*}{ Gold } & $\bar{M} \bar{a} \bar{l} \bar{i}$ & $1 \overline{7} . \overline{7}$ & & Algeria & 33.4 \\
\hline & Papua New Guinea & 14.5 & & Kazakhstan & 33.3 \\
\hline & Guyana & 14.0 & & Yemen & 30.6 \\
\hline & Kyrgyz Republic & 11.0 & & Iran, Islamic Rep. & 25.4 \\
\hline & Mongolia & 10.7 & & Norway & 17.6 \\
\hline \multirow[t]{2}{*}{ Iron } & Mauritania & $2 \overline{2} . \overline{2}$ & & Russian Federation & 14.7 \\
\hline & $\bar{B}^{-} \overline{r u n e}^{--}$ & $29 . \overline{2}$ & & Syrian Arab Republic & 14.3 \\
\hline \multirow{4}{*}{$\begin{array}{l}\text { Natural } \\
\text { Gas }\end{array}$} & Qatar & 26.5 & & Ecuador & 13.0 \\
\hline & Trinidad and Tobago & 20.1 & & Trinidad and Tobago & 12.7 \\
\hline & Algeria & 17.5 & & Sudan & 12.1 \\
\hline & Bolivia & 13.5 & $\overline{\text { Sugar }}$ & Guyana & 18.2 \\
\hline
\end{tabular}

The governments and private agents of commodity exporting countries have developed various ways of insuring themselves against commodity price risk. First, many governments have accumulated a buffer stock of assets in commodity-stabilization funds. To some extent, the saving is intended to deal with predictable exhaustion of the commodity resources, but it is also meant as precautionary savings against uncertainty in domestic output or in the price. There are, however, potential drawbacks to this strategy. For example, those funds may be misused because of weak governance leading to diversion for purposes other than insurance, or unsustainable management, like trying to offset a permanent shock. Furthermore, the accumulation of precautionary reserves comes at the cost of reducing consumption and welfare.

Insurance against price risk can also be achieved by the use of hedging instruments, whose welfare implications are studied in this paper. The market participants are typically large, but small agents can benefit indirectly, through their governments or financial intermediaries. Although these markets have developed significantly in recent years, economists have for some time wondered why they still remain so incomplete (short horizon), and why the existing instruments are not used to a larger extent (see, e.g., Caballero and Cowan (2007), Becker, Jeanne, Mauro and Rancière

$X / Y>5$ percent. The table reports the standard deviations of the log of commodity export and non-commodity income detrended with a time trend. The standard deviations by commodities are obtained as the simple average of country volatilities. 
Table 2. Standard deviation of the detrended log of commodity exports $(\tilde{X})$ and non-commodity $\operatorname{GDP}(\tilde{Y})$

\begin{tabular}{lccc}
\hline Commodity & $\sigma(\tilde{X})$ & $\sigma(\tilde{Y})$ & $\sigma(\tilde{X}) / \sigma(\tilde{Y})$ \\
\hline Aluminum & 0.18 & 0.09 & 2.0 \\
Cocoa & 0.30 & 0.18 & 1.6 \\
Copper & 0.38 & 0.17 & 2.3 \\
Fish & 0.20 & 0.11 & 1.8 \\
Gold & 0.32 & 0.11 & 3.0 \\
Iron & 0.16 & 0.08 & 2.0 \\
Natural Gas & 0.21 & 0.12 & 1.7 \\
Petroleum & 0.34 & 0.16 & 2.2 \\
Sugar & 0.18 & 0.09 & 1.9 \\
\hline
\end{tabular}

(2007) and Powell (1989)). Figure 1 shows the average open interest position and risk premium on oil futures in the New York Mercantile Exchange (NYMEX) market between 2003 and 2009. ${ }^{5}$ We see that most of the hedging is limited to maturities of less than three months as the risk premium becomes very large for longer maturities. ${ }^{6}$ Furthermore, the total open interest position in futures on the two largest markets for oil, the NYMEX and the Intercontinental Exchange (ICE), is currently around only 2.3 billions of barrels which is less than thirty days of world production and less than six weeks of world export. ${ }^{7}$ The limited extent of hedging is even more striking if compared with the size of proven oil reserves: the combined NYMEX and ICE open interest position is indeed less than 0.2 percent of known oil reserves. ${ }^{8}$

\section{THE MODEL}

The framework is an extension of the model of Jeanne and Sandri (2009) that incorporates hedging instruments. We consider a small open economy that is exposed to shocks in the price of the commodity that it exports. We first present the assumptions of the model with precautionary savings but no hedging (section $\mathrm{A}$ ) and then introduce futures into the model (section $\mathrm{B}$ ).

\footnotetext{
${ }^{5}$ The risk premium is computed as the average ex-post forecast error over the sample period.

${ }^{6}$ Lower risk premia are generally found using a longer time sample (Pagano and Pisani (2009)). Over the last five years oil prices have been mostly rising and therefore part of the gap between spot and futures prices can be due to a peso effect. Note that the limited availability of long-term contracts does not preclude long-term hedging, which can be partially achieved by rolling forward short-maturity contracts.

${ }^{7}$ Similar sizes of open interest position in futures relative to world production are also reported in the World Economic Outlook (2007, April) for natural gas, copper, corn, and soybeans.

${ }^{8}$ We underestimate the extent of hedging by leaving aside over-the-counter transactions (Campbell, Orskaug and Williams (2006)). However, open interest positions overestimate hedging by including contracts underwritten by speculators without a direct exposure to oil prices. The U.S. Commodity Futures Trading Commission reports that around 30 percent of the open interest positions on the NYMEX are held by speculators, and this share is likely to be higher on the ICE market which is subject to less stringent regulation.
} 


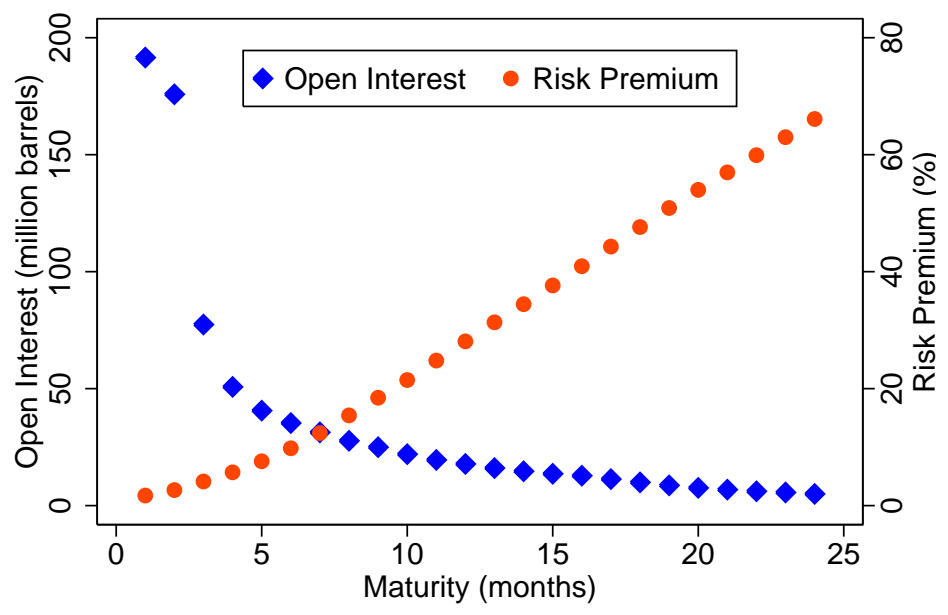

Figure 1. Average open interest and risk premium (NYMEX July 03 - May 09)

\section{A. No hedging}

We consider a small open economy producing an exportable good (the commodity) and populated by a representative infinitely-lived consumer. The consumer derives utility from consuming another good that we will call the consumption good. The consumption good will be used as numeraire. The representative consumer maximizes his utility

$$
U_{t}=E_{t} \sum_{i=0}^{\infty} \beta^{i} \frac{C_{t+i}^{1-\gamma}}{1-\gamma},
$$

subject to the budget constraint

$$
\frac{B_{t+1}}{1+r}+C_{t}=B_{t}+Y_{t}+X_{t}
$$

where $B_{t}$ is the consumer's holding of foreign assets at the beginning of period $t, r$ is the risk-free world interest factor, $Y_{t}$ is the domestic output of consumption good (non-commodity GDP), and $X_{t}$ is the level of commodity production (and exports) expressed in terms of consumption good.

In order to better focus on the consequences of uncertain export income, we assume that the domestic output of consumption good is deterministic, and grows by a factor $G$ in every period. Thus, the budget constraint can be rewritten in units of non-exportable income as

$$
b_{t+1}=\overbrace{\left(\frac{1+r}{G}\right)}^{R}\left(1+x_{t}+b_{t}-c_{t}\right)
$$

where lower-case variables are normalized by $Y_{t}$, for example $b_{t}=B_{t} / Y_{t}$.

The stochastic dynamics of the economy are driven by the normalized export income, $x_{t}$. Since we are interested primarily in the insurance of the price risk, we abstract from the quantity risk and 
assume that the country exports a constant normalized volume $q$ of commodity. Without hedging, thus, one has

$$
x_{t}=q p_{t},
$$

where $p_{t}$ is the spot price of the commodity. We assume that the spot price follows a multiplicative error process:

$$
p_{t+1}=\left(p+\rho\left(p_{t}-p\right)\right) \varepsilon_{t+1},
$$

where $p$ without time subscript is the average price, $\rho \leq 1$ is the persistence of the price process, and $\varepsilon_{t}$ is an i.i.d. positive random variable of mean one. ${ }^{9}$

We assume that the domestic consumer can borrow only against future export income and we rule out the possibility of default. ${ }^{10}$ Therefore, to ensure solvency the debt level can never be larger than the minimum present discounted value of future export income. More formally the country is subject to the no-default constraint:

$$
\frac{b_{t+1}}{R} \geq-\min _{t}\left(\sum_{i=1}^{+\infty} R^{-i} x_{t+i}\right)=-\Phi_{t}
$$

where the minimum is taken at time $t$ over all the possible paths $\left(x_{t+i}\right)_{i \geq 1}$. Let us define the operator $\underline{E}_{t} p_{t+i}$ which given the price level at $t$ returns the lowest possible price at $t+i$. This can be computed from equation (4) by assuming that the shock $\varepsilon$ is equal to its worst realization $\underline{\varepsilon}$ in every period between $t$ and $t+i$

$$
\underline{E}_{t} p_{t+i}=\underline{p}+(\underline{\varepsilon} \rho)^{i}\left(p_{t}-\underline{p}\right)
$$

where $\underline{p}=[1-(1-\underline{\varepsilon}) /(1-\rho \underline{\varepsilon})] p$ is the lower bound to which $p_{t}$ converges if the shock is always equal to $\underline{\varepsilon}$. In the absence of hedging, the maximum borrowing ability of the country can therefore be written as:

$$
\Phi_{t}=q \sum_{i=1}^{+\infty} R^{-i} \underline{E}_{t} p_{t+i}
$$

which, using (6), can be written as a linear function of the current price $p_{t}$.

In order to reduce the number of state variables in the consumer's optimization problem with hedging, it is useful to define the country's "pledgeable wealth" as

$$
w_{t} \equiv b_{t}+x_{t}+\Phi\left(p_{t}\right) \text {. }
$$

This is the sum of the country's external wealth and of its pledgeable intertemporal export income (the minimum present discounted value of export income that can be pledged in repayment to foreigners). As can be seen using (3) and (5), period- $t$ consumption must be lower than the

\footnotetext{
${ }^{9} \mathrm{We}$ do not use an AR1 in levels to rule out negative prices. We also prefer to avoid working with an AR1 in logs, which complicates the computation of conditional expectations and the pricing of futures contracts.

${ }^{10}$ We allow for default in section V.B in order to assess its potential as an alternative insurance mechanism.
} 
country's current non-export income plus its pledgeable wealth,

$$
c_{t} \leq 1+w_{t}
$$

The country's consumption/saving problem can thus be expressed in Bellman form as

$$
v\left(w_{t}, p_{t}\right)=\max _{c_{t}}\left\{u\left(c_{t}\right)+\beta G^{1-\gamma} E_{t} v\left(w_{t+1}, p_{t+1}\right)\right\}
$$

subject to

$$
\begin{aligned}
c_{t} & \leq 1+w_{t}, \\
w_{t+1} & =R\left(1+w_{t}-\Phi\left(p_{t}\right)-c_{t}\right)+q p_{t+1}+\Phi\left(p_{t+1}\right), \\
p_{t+1} & =\left(p+\rho\left(p_{t}-p\right)\right) \varepsilon_{t+1} .
\end{aligned}
$$

This yields the Euler equation

$$
c_{t}^{-\gamma}=\max \left[\frac{\beta(1+r)}{G^{\gamma}} E_{t}\left(c_{t+1}^{-\gamma}\right),\left(1+w_{t}\right)^{-\gamma}\right] .
$$

We assume the impatience condition

$$
\frac{\beta(1+r)}{G^{\gamma}}<1
$$

which, as discussed in Carroll (2008) and Jeanne and Sandri (2009), prevents degenerate solutions with infinite accumulation of foreign assets. ${ }^{11}$ We solve the problem numerically by policy function iteration as explained in appendix III. The dynamics of $w_{t}$ are then obtained from the intertemporal budget constraint (9) with $c_{t}=c\left(w_{t}, p_{t}\right)$. The dynamics of the net foreign asset position $b_{t}$ are derived by netting out current export income $x_{t}$ and $\Phi\left(p_{t}\right)$. As discussed in detail by Jeanne and Sandri (2009), the model features a target net foreign asset position, $\hat{b}$, towards which the economy tends to converge over time. ${ }^{12}$ The target could be positive or negative. It is increasing with the variance in export income and with the domestic consumer's patience.

We have not allowed the country to have both foreign assets and foreign liabilities at the same time, but a simple extension of the model makes this possible. Let us assume that the country has gross foreign assets $B_{t}^{\prime}$ and gross external debt $D_{t}$. Assets and liabilities bear the same interest rate $r$. There is furthermore an external credit constraint $D_{t} \leq \bar{D}_{t}$. It is generally assumed in the literature that the maximum level of gross debt $\bar{D}_{t}$ is proportional to the level of domestic output or of domestic collateral. The constraint involves gross debt because the foreign assets cannot be pledged in repayment to foreign creditors (they are protected by sovereign immunity).

Under these assumptions, the model endogenizes the difference $B_{t}=B_{t}^{\prime}-D_{t}$ but the levels of $B_{t}^{\prime}$ and $D_{t}$ are indeterminate. If we assume that the external credit constraint is binding $\left(D_{t}=\bar{D}_{t}\right)$, the

\footnotetext{
${ }^{11}$ This condition is sufficient if $\rho<1$. A stronger restriction is required if $\rho=1$.

${ }^{12}$ Formally the target is defined as the level of $b_{t}$ at which $E_{t} b_{t+1}=b_{t}$. For a formal proof of the existence of this target see Carroll (2008).
} 
model gives us a unique level of gross foreign assets $B_{t}^{\prime}$. We can think of $B_{t}^{\prime}$ as a commodity fund coexisting with external debt.

\section{B. Futures}

We now assume that export income can be hedged using futures or forward contracts. ${ }^{13}$ Futures allow the domestic consumer to secure a price $\theta$ periods ahead at a level given by the operator

$$
F\left(p_{t}, \theta\right)=\frac{E_{t}\left(p_{t+\theta} \mid p_{t}\right)}{1+\tau_{\theta}}=\frac{p+\rho^{\theta}\left(p_{t}-p\right)}{1+\tau_{\theta}},
$$

where $\tau_{\theta}$ is the premium on the future price, which could be positive because of investors' risk aversion or a liquidity premium.

One can use the premium $\tau$ to capture different assumptions about the availability of hedging instruments. For example, the absence of hedging instruments corresponds to $\tau_{\theta}=+\infty$ for $\theta \geq 1$. Hedging instruments whose liquidity decreases with the horizon can be modeled as an increasing path for $\tau_{\theta}$. Financial innovation can be defined as a reduction in $\tau$ at certain horizons.

Determining the optimal hedging policy for an arbitrary cost structure $\left\{\tau_{t}\right\}_{t=0, . .,+\infty}$ is a computationally demanding problem with a very large state and choice space. ${ }^{14}$ To simplify, we will assume that hedging is costless up to horizon $\theta$, and infinitely costly at longer horizons:

$$
\begin{aligned}
& \tau_{t}=0 \text { for } t \leq \theta, \\
& \tau_{t}=+\infty \text { for } t>\theta .
\end{aligned}
$$

It follows that the consumer hedges all the export income $\theta$ periods ahead. In the absence of risk premium, the futures are priced at their actuarially fair value, so that a risk-averse representative agent takes full advantage of them by hedging all his export income. Note that in this frictionless setting the country could achieve full insurance by rolling over one-year forwards. ${ }^{15}$ However, various costs associated with rolling over short-term contracts may limit the effectiveness of this strategy in practice. Alternatively, we could allow for rolling over the hedge forward at no cost and re-interpret $\theta$ as the horizon of the hedging strategy rather than the maturity of the underlying contracts.

\footnotetext{
${ }^{13}$ The difference between futures and forward contracts is that the former are traded in an organized market. The structure of the market does not matter for our results so that we will refer to the hedging instruments indifferently as futures or forward contracts.

${ }^{14}$ With positive finite risk premiums, we must solve for the share of production that the country wants to sell forward at each available maturity, thus enlarging the choice set. The state space would become much larger due to the need of keeping track of the share of production in each future year that has already been sold forward.

${ }^{15}$ Consider for example the case in which the country wants to secure at time $t$ the price at $t+2$ of $q$ commodity units. If two-year futures are available, the country could lock export revenues of $q\left(p+\rho^{2}\left(p_{t}-p\right)\right)$. The same result can be obtained by using one-year futures. By selling one year forward $q \rho / R$ and $q$ units at time $t$ and $t+1$ respectively, the country would secure revenues of $(q \rho / R)\left(p+\rho\left(p_{t}-p\right)-p_{t+1}\right) R+q\left(p+\rho\left(p_{t+1}-p\right)\right)$ at time $t+2$, equal to $q\left(p+\rho^{2}\left(p_{t}-p\right)\right)$.
} 
The introduction of futures improves the welfare of the representative consumer through two channels. The first channel involves smoothing export income and consequently consumption. The second, somewhat less obvious mechanism works through the country's "external balance sheet".

Regarding income smoothing, hedging allows the country to sell its commodity exports at the conditional expected price $\theta$ periods ahead, $\left(p+\rho^{\theta}\left(p_{t-\theta}-p\right)\right)$. Income volatility, thus, is reduced by the factor $\rho^{\theta}$. The reduction in income and consumption volatility increases with the horizon of hedging and decreases with the persistence of the price process. In particular, the volatility is reduced to zero by hedging at any horizon $\theta \geq 1$ if there is no persistence in the price process $(\rho=0)$. The associated benefits are conceptually similar to the welfare gains from eliminating the business cycle, as measured by Lucas (1987).

The balance-sheet benefits of futures are twofold. First, decreasing the volatility of income reduces the target level of net foreign assets, $\widehat{b}$. The country can thus "save on precautionary savings", and increase the present discounted value of domestic consumption without making any sacrifice in terms of consumption volatility. Second, the introduction of futures relaxes the external borrowing constraint. This effect is theoretically more subtle than the other ones but-as we will see-may have a larger impact on domestic welfare. We spend the rest of this section to explain it.

Let us assume that futures are introduced at time $t^{*}$ (starting from a situation without hedging instruments). The maximum borrowing capacity of the country increases from $\Phi_{t^{*}}$ given by (7) to

$$
\Phi_{t^{*}}^{f}=\overbrace{q \sum_{i=1}^{\theta} R^{-i} F\left(p_{t^{*}}, i\right)}^{\hat{\Phi}_{t^{*}}^{f}}+\overbrace{q \sum_{i=\theta+1}^{\infty} R^{-i} F\left(\underline{E}_{t^{*}} p_{t^{*}+i-\theta}, \theta\right)}^{\tilde{\Phi}_{t^{*}}^{f}},
$$

where the superscript $f$ is used to identify variables with a different definition under futures. The first term is the present discounted value of the export income that is sold forward in $t^{*}$, whereas the second term is the minimum present discounted value of the export income that will be sold after period $t^{*}+1$. Comparing (7) and (14) shows that hedging increases the country maximum borrowing capacity $\left(\Phi_{t^{*}}^{f}>\Phi_{t^{*}}\right)$. ${ }^{16}$ Hedging allows the country to secure a higher minimum level of export income, and so to issue more default-free debt. The minimum level of export income is increased by hedging because the exports that are sold forward are valued at the expected price rather than at the worst possible spot price that can be later obtained. ${ }^{17}$

The equilibrium can be solved for in the same way as in the model without hedging, as explained in more detail in Appendix II. The introduction of hedging increases pledgeable wealth to

$$
w_{t^{*}}^{f}=b_{t^{*}}+x_{t^{*}}+\Phi_{t^{*}}^{f} .
$$

\footnotetext{
${ }^{16}$ This results from the inequality $\underline{E}_{t} p_{t+i} \leq F\left(\underline{E}_{t} p_{t+i-\theta}, \theta\right)$ for $i \geq \theta$, which implies $\underline{E}_{t} p_{t+i} \leq F\left(p_{t}, i\right)$ for $i=\theta$. The inequality directly follows from (6) and (13).

${ }^{17}$ The country's borrowing capacity is determined by the minimum level of export income because of the assumptions that only export income is pledgeable and that debt is default-free.
} 
The transition equation for pledgeable wealth becomes,

$$
w_{t+1}^{f}=R\left(1+w_{t}^{f}-\tilde{\Phi}_{t}^{f}-c_{t}\right)+R^{-\theta} q F\left(p_{t+1}, \theta\right)+\tilde{\Phi}_{t+1}^{f} .
$$

In each year pledgeable wealth increases by the present discounted value of the commodity export $\theta$ periods ahead sold forward $R^{-\theta} q F\left(p_{t+1}, \theta\right)$, rather than by current export valued at the more volatile spot price $q p_{t+1}$. The maximization problem is equivalent to the one under no hedging, but with transition equation (16) for pledgeable wealth which at time $t^{*}$ is newly defined according to ( $15)$.

\section{THE WELFARE GAINS FROM HEDGING}

In this section we calibrate the model (in particular the process for $p_{t}$ ) using data on commodity prices, study the welfare gains from hedging, and discuss the sensitivity of the results to the key parameters. We conclude by reporting the welfare gains for some specific commodities.

\section{A. Calibration}

Our benchmark calibration is reported in Table 3. The values of $r, \gamma$, and $\beta$ are standard in the literature. We choose a deterministic growth rate of 1 percent and will discuss the sensitivity to this parameter in the next section.

Table 3. Benchmark calibration

\begin{tabular}{ccccccc}
\hline$r$ & $\gamma$ & $\beta$ & $G$ & $\rho$ & $\sigma$ & $q p$ \\
\hline 0.04 & 2 & $1.04^{-1}$ & 1.01 & 0.9 & 0.2 & 0.2 \\
\hline
\end{tabular}

The persistency and volatility of price shocks are calibrated by reference to the time series properties of commodity prices. We estimate the AR1 process with multiplicative error term in equation (4) using annual commodity price data taken from the International Financial Statistics and deflated by the export unit value for industrial countries. We assume that the error term is lognormally distributed with mean one and standard deviation $\sigma$, and perform the estimation using Maximum Likelihood as described in Appendix IV. The results are reported in Table 4 together with the ratios of commodity exports to non-export GDP, $q p$, obtained as the simple average of the data in Table 1.

As documented in the literature (Cashin, Liang and McDermott (2000)), we find that shocks to commodity prices are very persistent, with autocorrelation coefficients usually above 0.85 . Our benchmark value for the persistence parameter, 0.9 , is somewhat higher than the average level of $\rho$ across commodities (0.86), but lower than the estimated persistence for oil, which is the highest across all commodities in our sample and close to 1 . We find that the year-to-year volatility in the price varies from 10 to 40 percent depending on the commodity: in the calibration we choose $\sigma=0.2$, close to the cross-commodity average as well as the volatility of oil prices. Finally, we set 
Table 4. Calibration by commodity

\begin{tabular}{lccc}
\hline Commodity & $\rho$ & $\sigma$ & $q p(\%)$ \\
\hline Aluminum & 0.71 & 0.14 & 15.0 \\
Cocoa & 0.98 & 0.42 & 13.6 \\
Copper & 0.87 & 0.20 & 18.2 \\
Fish & 0.88 & 0.10 & 10.3 \\
Gold & 0.96 & 0.16 & 13.6 \\
Iron & 0.98 & 0.14 & 22.2 \\
Natural Gas & 0.97 & 0.27 & 21.4 \\
Petroleum & 0.98 & 0.21 & 38.0 \\
Sugar & 0.65 & 0.34 & 18.2 \\
\hline
\end{tabular}

the ratio of commodity export to non-commodity GDP to 20 percent, close to the average across commodities.

\section{B. Benchmark results}

By numerically solving the model, we find that under the benchmark calibration the country's target level of net foreign assets is equal to zero, $\hat{b}=0$. In other terms, the country's gross foreign assets fully cover its gross external debt. The impatience condition (12) is satisfied because of the positive growth in domestic income, against which the domestic consumer would like to borrow. Although impatience is generated by a relatively moderate growth rate in income (1 percent), the borrowing motive is sufficiently strong to dominate the precautionary savings motive, so that the country would like to be a net debtor. However, the country cannot be a net debtor because the process (4) implies that future export income could fall to zero with a nonzero probability. In the absence of hedging, thus, the country simply converges to a zero level of net foreign assets.

As common in the literature, we express the welfare gains from hedging in terms of the permanent percentage increase in annual consumption that yields the same welfare gain for the representative consumer in the economy without hedging (at the target level of net foreign assets, $b_{t^{*}}=\hat{b}$ and at the equilibrium price $p_{t^{*}}=p$ ). ${ }^{18}$ More formally, by exploiting the homotheticity of the CRRA utility function, the welfare gain from the introduction of hedging is defined as the $\alpha^{f}$ which solves:

$$
\left(1+\alpha^{f}\right)^{1-\gamma} v(w(\hat{b}, p), p)=v^{f}\left(w^{f}(\hat{b}, p), p\right),
$$

so that

$$
\alpha^{f}=\left(\frac{v^{f}\left(w^{f}(\hat{b}, p), p\right)}{v(w(\hat{b}, p), p)}\right)^{\frac{1}{1-\gamma}}-1
$$

\footnotetext{
${ }^{18}$ We could also obtain an unconditional measure of the welfare gain by taking the average of $\alpha^{f}$ over a large number of realizations of the states.
} 
As already discussed in section III.B, hedging improves welfare through two channels: first, by reducing the volatility of income; and second, by allowing the country to reduce its net foreign asset position. In order to measure the welfare gain from the first channel, we use the smoother income process allowed by hedging but keep the same consumption function (and so the same target level of assets) as in the absence of hedging. We are therefore exclusively assessing the gains from reducing the income and consumption variance, without allowing for the optimal depletion of the net foreign asset position.

Figure 2 shows the welfare gains from futures as a function of their maturity (the case where the policy functions are held constant is denoted with an upper bar on the variable names). We observe that 1-year forward contracts yield relatively small welfare gains, equivalent to a permanent increase in annual consumption of less than one-tenth of a percent, similar to the benefits from eliminating the business cycle as quantified by Lucas (1987). ${ }^{19}$ Even extending the maturity to twenty years provides the country with limited gains, less than one half of a percent.

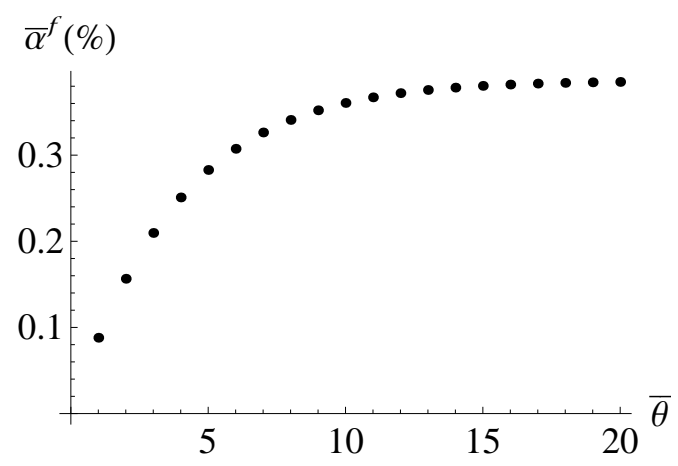

Figure 2. Welfare gains from consumption smoothing only (holding constant the target level $\hat{b}$ )

Figure 3 reports the welfare gains from futures contracts once we allow the country to optimally adjust its net foreign asset position. The welfare gains are about ten times larger than in the previous case. One-year forward contracts with endogenous net foreign asset position leads to welfare gains equivalent to a permanent increase in consumption of more than one percent. Forward contracts with maturity of five years multiply these gains by more than three. Furthermore, the gains are marginally decreasing with the maturity, so that 10 -year contracts provides most of the benefits.

The reason behind the much larger welfare gains from hedging with endogenous net foreign assets is that the introduction of futures allows the country to boost consumption by consuming a fraction of precautionary assets or by issuing debt. This can be seen from the left panel of Figure 4, which shows the variations of the consumption function with the normalized net foreign assets, $b .{ }^{20}$ The curve labeled with $\theta=0$ corresponds to the case without hedging, whereas the other curves correspond to futures of maturities $\theta$ equal to 1,3 and 10 years and infinity. We observe that the

\footnotetext{
${ }^{19}$ Pallage and Robe (2003) have found business cycle fluctuations to be more costly in developing countries than in advanced ones because their economies are more volatile.

${ }^{20}$ The consumption functions are solved in the $\left(w_{t}, p_{t}\right)$ state space. Figure 4 shows the consumption function assuming that the commodity price is equal to its average, $p$.
} 


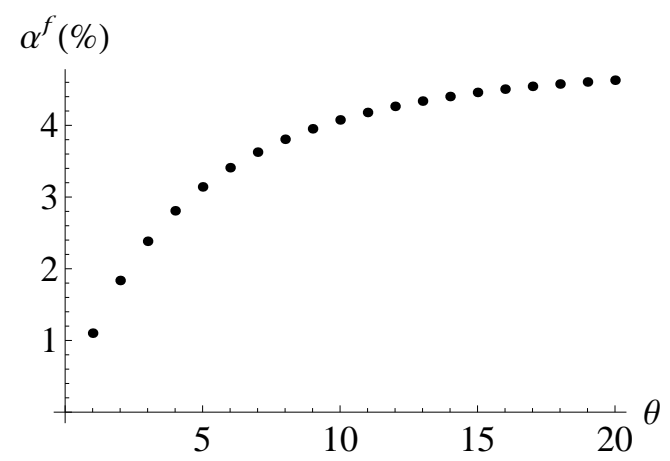

Figure 3. Full welfare gains (allowing for the optimal reduction in $b_{t}$ )

introduction of futures boosts consumption, which is financed by depleting the net foreign asset position. The right-hand side panel shows how the target for net foreign assets decreases with the maturity of hedging instruments, from a debt of about 80 percent of income for one-year contracts to a debt amounting to five years of income for twenty-year contracts.
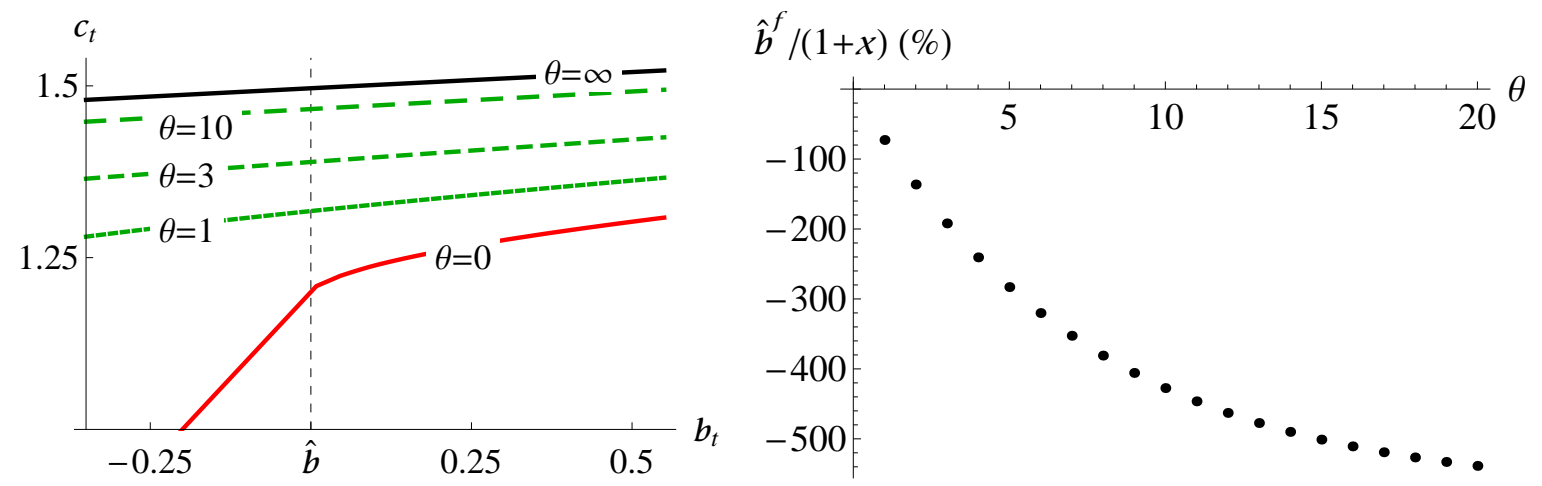

Figure 4. Consumption functions and target net foreign asset position

The fact that the introduction of hedging leads to the reduction of foreign assets raises interesting questions about the distribution of the welfare gains over time. Figure 5 shows, on the left-hand side, the dynamics of the net foreign asset position in the absence of price shocks following the introduction of futures with maturities of respectively one, five and ten years. On the right-hand side, we plot the change in consumption induced by hedging computed $j$ years after the introduction of futures.

The impact of hedging on domestic consumption is positive over the first ten years, but turn negative after that due to the service of foreign debt. Consumption is reduced by more than 5 percent forty years after the introduction of 5-year forward contracts. This suggests that in an overlapping-generations model, expanding the hedging possibilities would increase the welfare of current generations at the cost of future generations. ${ }^{21}$

\footnotetext{
${ }^{21}$ Indeed, our model can be interpreted as one with overlapping generations and perfectly altruistic (but impatient) parents. It is perfectly equivalent to assume that individuals are infinitely-lived or that they care about their offsprings as much as about themselves.
} 

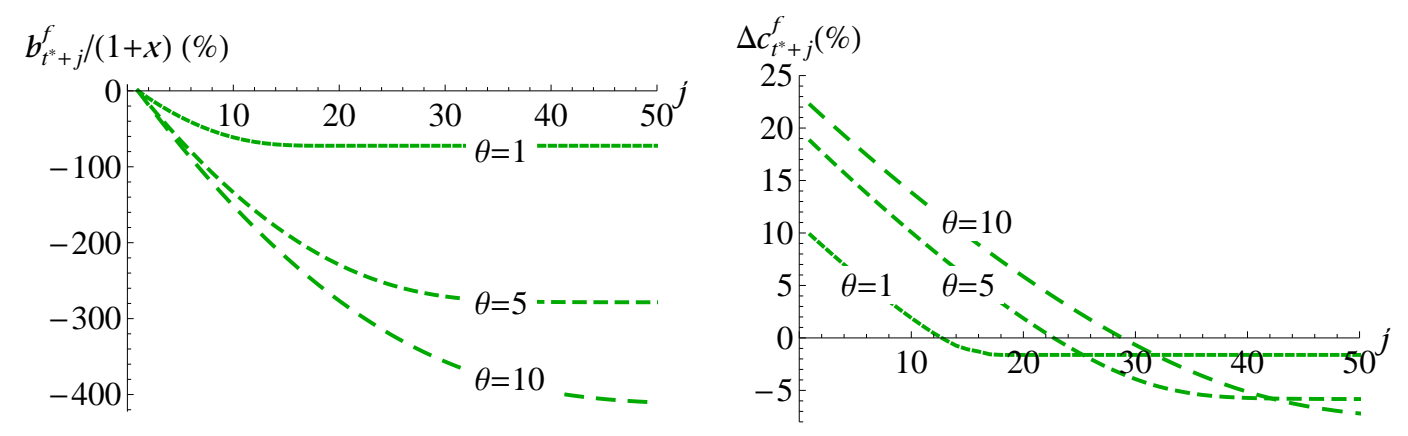

Figure 5. Dynamics of net foreign assets and consumption following the introduction of hedging

\section{Sensitivity analysis}

Under the benchmark calibration, the model leads to three main results. First, the welfare gains from forward contracts can be large. Second, most of the welfare gains come from the relaxation of the borrowing constraint. Third, contracts with medium-term maturities already provide most of the gains. We now discuss the sensitivity of these results to alternative parameter values.

We investigate first the role of the intertemporal discount factor and of the growth rate, with and without allowing for changes in foreign assets. These are important parameters since they alter the consumer's level of impatience and thus his desire to borrow against future income. Figure 6 shows that as we reduce the discount rate by increasing the value of $\beta$, the country targets a larger net foreign asset position as a percentage of GDP. As $\beta$ approaches $G^{\gamma} / R$ the impatience condition (12) becomes an equality and the foreign asset target goes to infinity.

Intuitively, a higher degree of patience should reduce the utility cost of holding precautionary assets and so should also reduce the welfare gains from substituting those assets by hedging. The top-right panel of Figure 6 confirms that this is indeed the case. The figure shows how the welfare gains from hedging at an infinite horizon vary with $\beta$ under two assumptions: if the country does not adjust its foreign assets target $(\bar{\theta}=+\infty)$ and if it does $(\theta=+\infty)$. As $\beta$ increases, the welfare gains coming from the balance sheet channel, measured by the gap between the two curves, shrinks and converges to zero as $\beta$ comes close to its upper bound. This is so even though hedging reduces the level of precautionary foreign assets by a very large amount when $\beta$ is large. The large reduction in foreign assets does not lead to large welfare gains because the consumer is patient and does not suffer much from postponing consumption. The main lesson from Figure 6 is that hedging yields large welfare gains if the domestic consumer is impatient, and it does so by relaxing his external borrowing constraint.

The bottom panels of Figure 6 show the variations of the target level of foreign assets and of the welfare gains from hedging with the growth rate. Increasing the growth rate has the same effect as decreasing patience since this makes the consumer more willing to borrow against future income. Thus the welfare gains from relaxing the borrowing constraint increase with the growth rate.

We now consider the sensitivity of the results to the properties of the price process. The left-hand side plot of Figure 7 shows that under the benchmark calibration, changing the persistence of the 

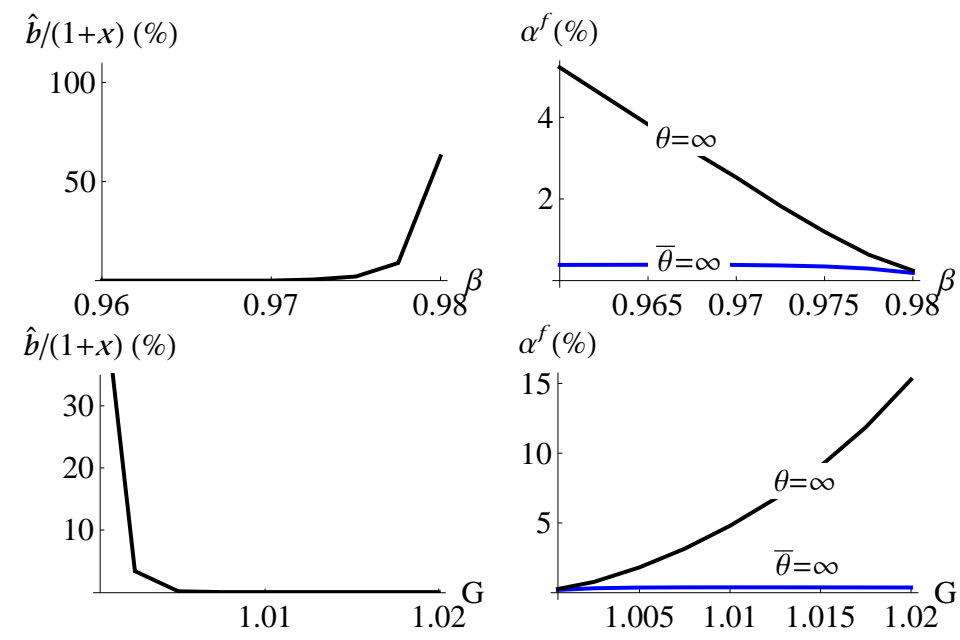

Figure 6. Welfare gains as a function of discount factor and growth rate

price process, $\rho$, does not affect the target level for foreign assets, which remains equal to zero. The middle plot displays the welfare gains from moving to full insurance (i.e., with forward contracts of infinity maturity) respectively with and without allowing the country to borrow. We observe that while the welfare gains from a smoother income are relative small, they become significant if the income shock is very persistent. This is simply due to the fact that the unconditional variance of the price process increases with its persistence.
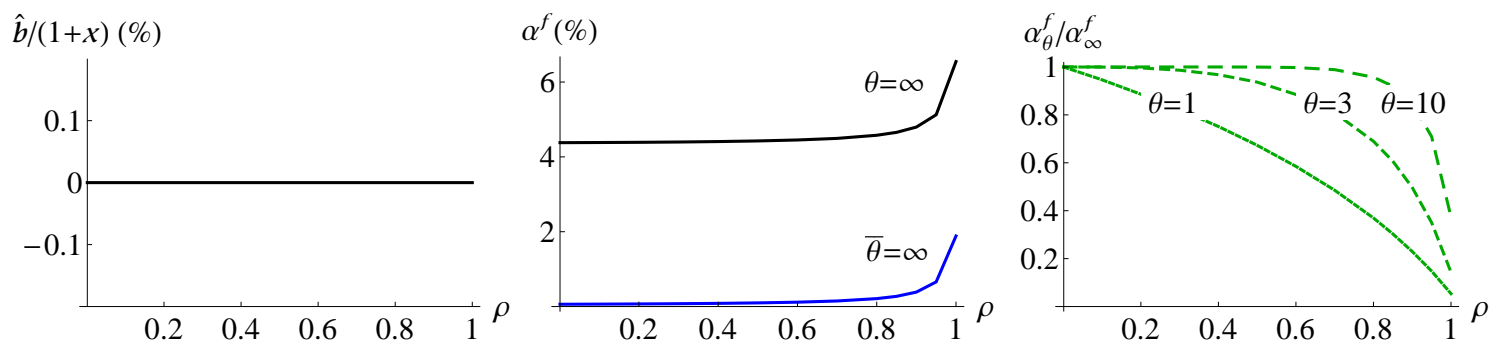

Figure 7. Welfare gains as a function of the shock persistency, $\rho$

Finally, the right-hand side plot shows the fraction of the welfare gains from full insurance that can be obtained with futures of finite maturities. The figure reveals that if the shocks are fully transitory $(\rho=0)$, even a one-year forward contract is able to provide the country with complete insurance. This is easily understood by considering that with transitory shocks the expectation of tomorrow's price is always equal to its average. As the persistence of the shock increases, short-horizon contracts yield a lower share of the maximum welfare gains. At very high persistence we observe that even ten-year forward contracts provide the country with only around fifty percent of the welfare gains from full insurance.

The sensitivity of the welfare gains to the standard deviation of the shock in export income is shown in Figure 8. In the absence of hedging, higher volatility leads to a larger stock of precautionary savings. The welfare gains from moving to full insurance are also increasing with the volatility of the price innovation, and the gains from income smoothing become significant for high 
levels of income volatility. We also see that the welfare gains from increasing the horizon of hedging are not sensitive to the level of income volatility.
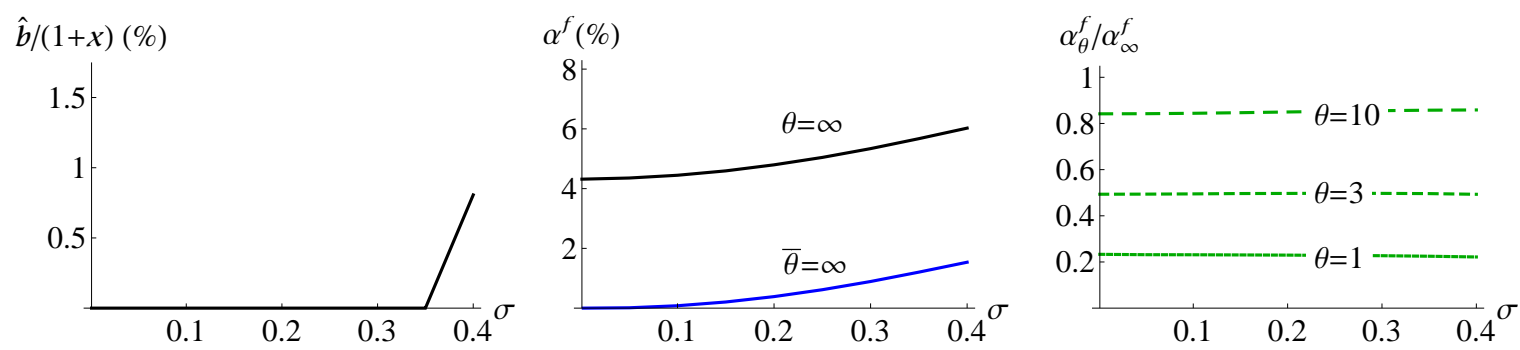

Figure 8. Welfare gains as a function of the shock variance, $\sigma$

Summing up, the welfare gains from hedging export income may be much larger than the welfare costs of the business cycle. This is because hedging does more than simply smoothing the consumer's income: it also relaxes the country's external borrowing constraint, which yields a large welfare gain if the consumer is impatient.

\section{Welfare gains by commodities}

Having quantified the welfare gains under our benchmark calibration and discussed their sensitivity, we now calibrate the model using data on key commodities. Table 5 reports the welfare results, computed using the parameters from Table 4. The first two columns report the benefits of full insurance, respectively with and without adjustment of the target level for foreign assets. The subsequent columns report the gains reaped with forward contracts of maturities of 1, 3, 5, 10 and 20 years.

Table 5. Welfare gains from futures by commodity

\begin{tabular}{llllllll}
\hline Commodity & $\alpha_{\infty}^{f}$ & $\bar{\alpha}_{\infty}^{f}$ & $\alpha_{1}^{f}$ & $\alpha_{3}^{f}$ & $\alpha_{5}^{f}$ & $\alpha_{10}^{f}$ & $\alpha_{20}^{f}$ \\
\hline Aluminum & 3.8 & 0.0 & 1.7 & 3.0 & 3.4 & 3.8 & 3.8 \\
Cocoa & 6.3 & 2.5 & 0.5 & 1.3 & 2.0 & 3.3 & 4.8 \\
Copper & 4.5 & 0.3 & 1.2 & 2.5 & 3.2 & 4.0 & 4.4 \\
Fish & 3.1 & 0.0 & 0.7 & 1.5 & 2.0 & 2.6 & 3.0 \\
Gold & 3.9 & 0.2 & 0.5 & 1.2 & 1.7 & 2.5 & 3.3 \\
Iron & 5.4 & 0.7 & 0.5 & 1.2 & 1.8 & 2.8 & 4.0 \\
Natural Gas & 6.7 & 2.0 & 0.7 & 1.7 & 2.5 & 4.0 & 5.4 \\
Petroleum & 8.7 & 2.8 & 0.9 & 2.3 & 3.3 & 5.2 & 7.1 \\
Sugar & 4.5 & 0.3 & 2.4 & 3.8 & 4.2 & 4.5 & 4.5 \\
\hline
\end{tabular}

We observe that the welfare gains from hedging are potentially very large, ranging from 3 percent to more than 8 percent of consumption in the case of Petroleum. As discussed in section $\mathrm{C}$, the benefits are increasing with the persistence and variance of the price shocks and are obviously greater for countries whose commodity export income accounts for a larger share of total GDP. 
Countries exporting commodities with low shock persistence, such as Aluminium, obtain most of the gains from hedging at relatively short maturities, while exporters of commodities subject to more persistent shocks, like Petroleum, derive large welfare benefits from extending the horizon of hedging.

\section{EXTENSIONS}

We present two extensions of the model. In the first one, the insurance against the commodity price risk is achieved through options rather than forward contracts. In the second extension, we allow for defaultable debt and study its ability to act as an insurance mechanism when default occurs in response to large negative shock prices.

\section{A. Options}

Forward contracts help the country to avoid negative shocks to commodity prices, but at the same time prevent it from reaping the gains of positive fluctuations. Governments can therefore be reluctant to adopt this hedging strategy since strong political opposition can arise during periods of increasing commodity prices. A more politically viable alternative may be to insure exclusively against the downside risk by purchasing put options that pay off only if the price of the commodity falls below the strike price. This section looks at the welfare gains from hedging price risk with options of different maturities and with different strike prices.

Assume that options of maturity $\theta$ are unexpectedly introduced at time $t^{*}$. The strike price is constant and equal to a fraction $\zeta$ of the equilibrium price $p$. Consistent with our assumptions about futures, we assume that options are sold at the fair risk-neutral price, so that the country will buy enough options to fully cover its export income.

At the time when options are introduced, the maximum amount of default free borrowing for the representative consumer is given by:

$$
\Phi_{t^{*}}^{o}=\overbrace{-q \sum_{i=1}^{\theta} \xi_{i}\left(p_{t^{*}}\right)}^{\hat{\Phi}_{t^{*}}^{o}}+\overbrace{q \sum_{i=1}^{\infty} R^{-i}\left[\max \left(\underline{E}_{t^{*}} p_{t^{*}+i}, \zeta p\right)-\xi_{\theta}\left(\underline{E}_{t^{*}} p_{t^{*}+i}\right)\right]}^{\tilde{\Phi}_{t^{*}}^{o}},
$$

where we use superscript $o$ to distinguish variables that refer to options, and $\xi_{i}\left(p_{t}\right)$ is the price of an option with maturity $i$ and strike price $p \zeta$ when the export price is $p_{t}$. The first term corresponds to the cost of the options purchased at time $t^{*}$. The second term reflects the minimum present value of future export income net of the cost of buying the options. We use the fact that $\max \left(p_{t+i}, \zeta p\right)-\xi_{\theta}\left(p_{t+i}\right)$ is increasing with $p_{t+i}$ and so is minimized for $p_{t+i}=\underline{E}_{t} p_{t+i}$.

The country's pledgeable wealth at the time of the introduction of options is thus given by:

$$
w_{t^{*}}^{o}=b_{t^{*}}+x_{t^{*}}+\Phi_{t^{*}}^{o}
$$


with transition equation:

$$
w_{t+1}^{o}=R\left(1+w_{t}^{o}-\tilde{\Phi}_{t}^{o}-c_{t}\right)+q\left[\max \left(p_{t+1}, \zeta p\right)-\xi_{\theta}\left(p_{t+1}\right)\right]+\tilde{\Phi}_{t+1}^{o} .
$$

Using the same solution procedure as for futures and under the benchmark calibration in Table 3, we compute the welfare gains from introducing options with different maturities and strike prices. 22 The results are shown in Figure 9. The dotted lines correspond to the case of options with strike prices at respectively 40,60 and 80 percent of the average price. As shown by the left-hand side panel, options allow the country to issue more default-free debt by limiting the downside risk in export income. This benefit is increasing with the strike price. The welfare gains from options are increasing with their horizon and with the strike price.

For comparison, the continuous line reports the results with futures. Futures dominate options because they hedge the risk on both sides. ${ }^{23}$ However for maturities shorter than five years, most of the welfare gains from futures can be captured by options, including relatively inexpensive options with low strike prices. This is no longer the case at longer maturities, for which high strike prices are required to make options a good substitute to futures.
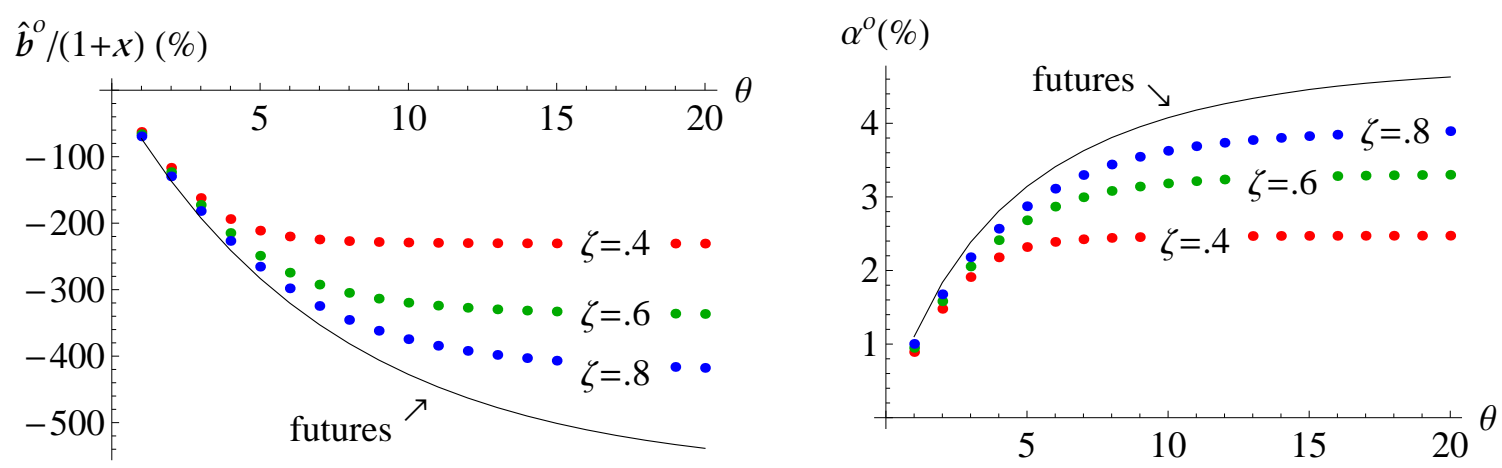

Figure 9. Net foreign assets and welfare gains with options and futures contracts

\section{B. Default}

Defaultable debt may reduce the welfare gains from hedging in two ways. First, default itself may be viewed as a substitute to hedging if it tends to occur when the price of the commodity export is low. ${ }^{24}$ Second, allowing the country to default will relax the no-default constraint and allow impatient countries to issue more debt—which was an important benefit from hedging. Since

\footnotetext{
${ }^{22}$ The option price $\xi_{\theta}\left(p_{t}\right)$ is computed numerically using Monte Carlo simulations.

${ }^{23}$ The options become equivalent to futures as the strike price goes to infinity.

${ }^{24}$ The country could insure itself perfectly by issuing liabilities that are contingent on the commodity price. There is a line of literature on sovereign debt that views default as a way of approximating the optimal state contingency (see, e.g., Grossman and Van Huyck (1988).
} 
default occurs in the real world, it seems important to see the extent to which defaultable debt provides a substitute for hedging.

More formally, we assume that the country defaults entirely on its foreign debt if the export price falls below a certain percentage threshold of the equilibrium price, $\zeta p$. There is no repayment following a default (the debt is completely erased). We assume that defaulting is costless: this entails no loss of output, the country maintains access to international debt market and foreigners are willing to purchase defaultable debt without requiring a pure risk premium compensating for risk aversion (although there is a default risk premium compensating for the probability of default). These assumptions obviously bias the analysis in favor of default, so that the following estimates should be viewed as an upper bound for the welfare gains from defaultable debt.

Defining $\pi_{t, i}$ as the default probability $i$ periods ahead from time $t$, the equilibrium gross interest rate on defaultable debt of maturity $\theta$ is given by:

$$
R^{\theta} / \prod_{i=1}^{\theta}\left(1-\pi_{t, i}\right) .
$$

Since default is assumed to happen only if the price falls below $\zeta p$, the country is still subject to the "natural" constraint of limiting the amount of borrowing to what it can repay in the worst possible scenario. The worst possible outcome for the country in the presence of default, is the one in which the export price drops permanently to exactly $\zeta p$, which leads to the minimum present discounted value of export income,

$$
\Phi_{t}^{d}=q\left(\frac{\zeta p\left(1-\pi_{t, 1}\right)}{R}+\frac{\zeta p\left(1-\pi_{t, 1}\right)\left(1-\pi_{t, 2}\right)}{R^{2}}+\ldots\right)
$$

where the subscript $d$ denotes the variables if debt is defaultable.

Let us assume that debt becomes defaultable at some time $t^{*}$. The country's pledgeable wealth is now given by,

$$
w_{t^{*}}^{d}=b_{t^{*}}+x_{t^{*}}+\Phi_{t^{*}}^{d},
$$

with the transition equations:

$$
w_{t+1}^{d}= \begin{cases}a_{t} R /\left(1-\pi_{t, 1}\right)+q p_{t+1}+\Phi_{t+1}^{d} & \text { if } a_{t}<0 \text { and } p_{t+1} \geq p \zeta \\ q p_{t+1}+\Phi_{t+1}^{d} & \text { if } a_{t}<0 \text { and } p_{t+1}<p \zeta \\ a_{t} R+q p_{t+1}+\Phi_{t+1}^{d} & \text { if } a_{t}>0\end{cases}
$$

where $a_{t}=1+w_{t}^{d}-c_{t}-\Phi_{t}^{d}$ is the net foreign asset position at the end of period $t$ after consumption occurs.

As in the case of options and futures, the welfare gains from defaultable debt are closely related to the relaxation of the borrowing constraint. A higher default threshold $\zeta$ increases the level of export income the country can borrow against $\zeta p$, but also the probability of default and consequently the default risk premium. The impact of the default threshold on the borrowing ability of the country is 
therefore non monotonic as shown in Figure 10. We see that the maximum borrowing potential is achieved at a low levels of $\zeta$, around 30 percent, and so are the maximum welfare gains, which can reach almost 2 percent of consumption. Somewhat unexpectedly, the possibility of default leads to the highest benefits when its occurrence is limited to very low prices. In this way, the country insures itself from the worst tail events and maximizes its borrowing capacity. ${ }^{25}$
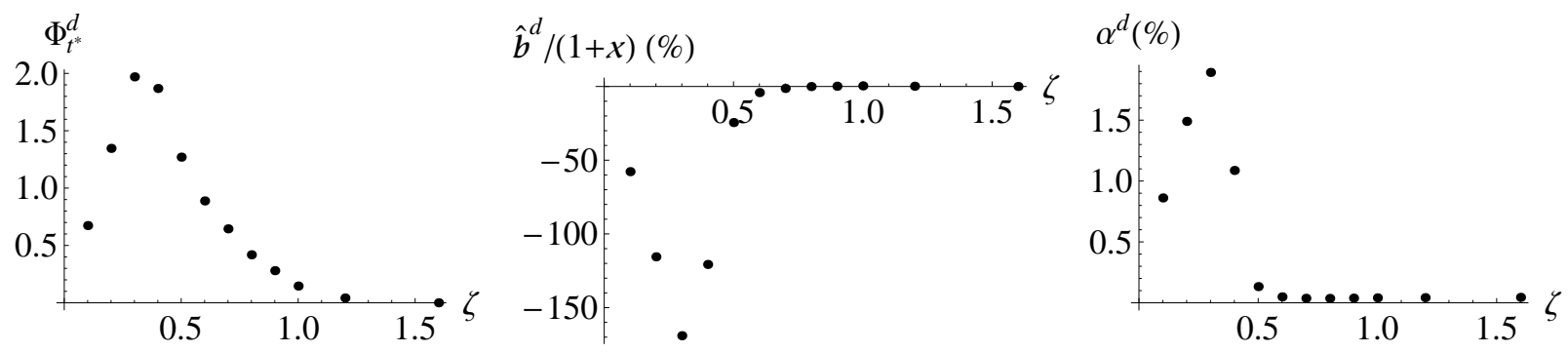

Figure 10. Borrowing capacity, equilibrium net foreign assets and welfare gains with defaultable debt

Defaultable debt is a form of insurance and yields some welfare gains. However, it is dominated by a combination of non-defaultable debt and hedging (provided that hedging instruments are available at a sufficiently long horizon). This is so even though we made the unrealistic assumption that default did not involve any cost in terms of output or credibility. Such costs would reduce further the net value of defaultable debt as a form of insurance.

\section{Conclusion}

Many developing countries receive a large share of their national income by exporting a single commodity. These countries are severely exposed to the fluctuations in commodity prices which tend to be very volatile and persistent. In this paper we developed a small open economy model in order to investigate the welfare gains that hedging strategies can provide to commodity exporters.

The availability of insurance instruments leads to two sources of gains. First, it reduces the export income volatility, allowing for a smoother consumption path. Second, it allows the country to reduce its net foreign assets, and to issue more default-free debt against future export income (the balance sheet channel).

Under our benchmark calibration, the introduction of forward contracts with ten-year maturity can lead to substantial welfare gains, equivalent to a four percent permanent increase in consumption. Most of the benefits come from the balance sheet channel, and depend on the country's degree of "impatience", i.e., its propensity to borrow against future export income. A country with a low intertemporal discount factor does not make a large sacrifice by maintaining a large stock of

\footnotetext{
${ }^{25}$ These results, however, clearly depend on the parameters of the model and in particular on the impatience factor. With a lower discount factor or growth rate, the country's desire to borrow against future income decreases and the relative importance of reducing the volatility of income increases. Therefore, a higher $\zeta$ with more frequent default becomes more appealing.
} 
precautionary savings. Hedging is much more beneficial for fast-growing emerging market economies that are willing to borrow against higher future income. Those welfare gains come from a debt-financed consumption boom that lasts about a decade and is followed by relatively lower consumption to repay the debt. Finally, we have shown that options can be a valid substitute to futures, while defaultable external debt is a less efficient form of insurance even if one leaves aside the default costs.

Regarding future research, it would be interesting to endogenize investment in the model. In this paper we have focused exclusively on the gains from smoothing consumption. However, hedging is likely to increase welfare also by reducing the uncertainty in investment in the commodity sector, if this leads to an expansion of productive capacity. Another useful extension of the model would be to consider the dependence of government fiscal revenues on commodity exports. In the countries where fiscal revenues are sensitive to commodity prices, hedging may lead to additional gains that are not captured by our model. More generally, the type of models that we use in this paper can be used to quantify the benefits of hedging against other country risks such as natural disasters or sudden stops in capital flows. 


\section{REFERENCES}

Arrau, Patricio, and Stijn Claessens, 1992, “Commodity Stabilization Funds," World Bank Policy Research Working Paper WPS 835.

Becker, Torbjorn, Olivier Jeanne, Paolo Mauro, and Romain Rancière, 2007, "Country Insurance: The Role of Domestic Policies," Occasional Paper No. 254, IMF.

Bems, Rudolfs, and Irineu de Carvalho Filho, 2009, "Current Account and Precautionary Savings for Exporters of Exhaustible Resources," IMF Working Paper 09/33.

Caballero, Ricardo J., and Kevin N. Cowan, 2007, "Financial Integration Without the Volatility," Unpublished.

, and Stavros Panageas, 2008, "Hedging Sudden Stops and Precautionary Contractions," Journal of Development Economics, Vol. 85, pp. 28-57.

Campbell, Patrick, Bjorn-Erik Orskaug, and Richard Williams, 2006, "The Forward Market for Oil," Bank of England Quarterly Bulletin, pp. 66-74.

Carroll, Christopher D., 2006, “The Method of Endogenous Gridpoints for Solving Dynamic Stochastic Optmization Problems," Economic Letters, pp. 312-320. 2008, "Theoretical Foundation of Buffer Stock Saving," Unpublished.

Cashin, Paul, Hong Liang, and C. John McDermott, 2000, "How Persistent Are Shocks to World Commodity Prices?," IMF Staff Papers, Vol. 47, No. 2, pp. 177 - 217.

Deaton, Angus, 1991, “Saving and Liquidity Constraints,” Econometrica, Vol. 59, No. 5, pp. 1221 1248.

Durdu, Ceyhun Bora, Enrique G. Mendoza, and Marco E. Terrones, 2009, "Precautionary Demand for Foreign Assets in Sudden Stop Economies: an Assessment of the New Merchantilism," Journal of Development Economics, Vol. 89, pp. 194 - 209.

Engel, Eduardo, and Rodrigo Valdés, 2000, “Optimal Fiscal Strategy for Oil Exporting Countries,” IMF Working Paper 00/118.

Ghosh, Atish R., and Jonathan D. Ostry, 1997, "Macroeconomic Uncertainty, Precautionary Saving and the Current Account,” Journal of Monetary Economics, Vol. 40, No. 1, pp. 121-139.

Grossman, Herschel, and John Van Huyck, 1988, "Sovereign Debt as a Contingent Claim: Excusable Default, Repudiation, and Reputation," American Economic Review, Vol. 78, No. 5, pp. 1088-97.

Jeanne, Olivier, and Damiano Sandri, 2009, "Optimal Precautionary Savings for Commodity Exporters," Manuscript in progress.

Lucas, Robert E., 1987, Models of Business Cycles (Basil Blackwell, New York). 
Pagano, Patrizio, and Massimiliano Pisani, 2009, "Risk-Adjusted Forecasts of Oil Prices," European Central Bank Working Paper No.999.

Pallage, Stephane, and Michel A. Robe, 2003, "On the Welfare Cost of Business Cycles in Developing Countries," International Economic Review, Vol. 44, No. 2, pp. 677-98.

Powell, Andrew, 1989, “The Management of Risk in Developing Country Finance," Oxford Review of Economic Policy, Vol. 5, No. 4, pp. 69-87.

World Economic Outlook, 2007, April, International Monetary Fund. 


\section{Appendix I. Commodity Price Data}

Table 6. Commodity price data from International Finance Statistics

\begin{tabular}{llc}
\hline Commodity & IFS name & price data coverage \\
\hline Aluminum & Aluminum: Canada & $1957-2007$ \\
Cocoa & Cocoa beans: Ghana & $1955-2007$ \\
Copper & Copper: United Kingdom & $1957-2007$ \\
Fish & Fish: Norway & $1980-2007$ \\
Gold & Gold: United Kingdom & $1963-2007$ \\
Iron & Iron Ore: Brazil & $1955-2007$ \\
Natural Gas & Natural Gas: Russian Federation & $1985-2007$ \\
Petroleum & Petroleum West Texas Intermediate & $1959-2007$ \\
\hline
\end{tabular}

\section{APPENDIX II. MODEL WITH HEDGING}

Pledgeable wealth is given by

$$
w_{t}^{f}=b_{t}+x_{t}+\Phi_{t}^{f},
$$

where pledgeable future export income can be decomposed in two terms, the export income that has already been sold forward, $\hat{\Phi}_{t}^{f}$, and the minimum value of the export income that will be sold forward in the future, $\tilde{\Phi}_{t}^{f}$

$$
\Phi_{t}^{f}=\hat{\Phi}_{t}^{f}+\tilde{\Phi}_{t}^{f} .
$$

The second term can be computed by using (6) and (13) to substitute out $F\left(\underline{E}_{t} p_{t+i-\theta}, \theta\right)$,

$$
\begin{aligned}
\tilde{\Phi}_{t}^{f} & =q \sum_{i=\theta+1}^{\infty} R^{-i} F\left(\underline{E}_{t} p_{t+i-\theta}, \theta\right), \\
& =\frac{q}{R^{\theta}}\left[\frac{\left(1-\rho^{\theta}\right) p+\rho^{\theta} \underline{p}}{R-1}+\frac{\underline{\varepsilon} \rho^{\theta+1}}{R-\underline{\varepsilon} \rho}\left(p_{t}-\underline{p}\right)\right] .
\end{aligned}
$$

The expressions for $x_{t}$ and $\hat{\Phi}_{t}$ depend on whether the futures were introduced more or less than $\theta$ periods before. When the futures are introduced $\left(t=t^{*}\right)$, we have $x_{t^{*}}=q p_{t^{*}}$ and $\hat{\Phi}_{t^{*}}$ is given by the first term on the r.h.s. of equation (14).

For $t=t^{*}+1, \ldots, t^{*}+\theta-1$, the current export income has been sold forward at time $t^{*}$ so that $x_{t}=q F\left(p_{t^{*}}, t-t^{*}\right)$. Future export income has been sold forward either in $t^{*}$ or in the following periods,

$$
\hat{\Phi}_{t}^{f}=q \sum_{i=1}^{t^{*}-t+\theta} R^{-i} F\left(p_{t^{*}}, t-t^{*}+i\right)+q \sum_{i=t^{*}-t+\theta+1}^{\theta} R^{-i} F\left(p_{t+i-\theta}, \theta\right) .
$$


For $t \geq \theta$ the economy enters the regime in which the export income has been sold forward $\theta$ periods before. We have $x_{t}=q F\left(p_{t-\theta}, \theta\right)$ and

$$
\hat{\Phi}_{t}^{f}=q \sum_{i=1}^{\theta} R^{-i} F\left(p_{t+i-\theta}, \theta\right) .
$$

In all cases we have

$$
\hat{\Phi}_{t+1}^{f}=R \hat{\Phi}_{t}^{f}-x_{t+1}+R^{-\theta} q F\left(p_{t+1}, \theta\right) .
$$

Using this equation and the budget constraint (3) it is then easy to prove (16).

\section{APPENDIX III. NOTES ON NUMERICAL SOLUTION}

The model is solved with policy function backward iteration over the state space $\left(w_{t}, x_{t}\right)$, following the endogenous gridpoints method proposed by Carroll (2006). We discretize the end-of-period savings $\left(1+w_{t}-c_{t}-\Phi_{t}\right)$ over the interval $[0,350]$, and $x_{t}$ over $[0,10 x]$ using respectively 50 and 20 points with a triple exponential growth. Policy functions over the entire state space are constructed with linear interpolation. To limit the interpolation error for the value function, we interpolate its transformation $\left((1-\gamma) v_{t}\right)^{(1 /(1-\gamma))}$. The grid to test for convergence is constructed with 10 values for $w_{t}$ and 10 for $x_{t}$, drawn with triple exponential growth respectively between $[0,30]$ and $[0,5 x]$. The price shock $\varepsilon_{t+1}$ is discretized using 7 equally likely bins with the addition of a zero realization with one out of a million probability mass. We have also experimented using Gauss-Hermite quadrature instead of equally likely bins and obtained very similar results.

The welfare gains using the consumption function solved under no hedging in Figure 2 have been computed with 10, 000 Monte Carlo simulations of income and consumption over 250 years. Monte Carlo simulations have also been used to compute option prices and default probabilities, simulating 1,000, 000 income patterns starting from 40 different values for $x_{t}$ drawn from the interval $[0,20 x]$ with triple exponential growth rate.

\section{APPEndix IV. MAXimum Likelihood Estimation}

Consider the price process:

$$
p_{t}=\overbrace{\left(p+\rho\left(p_{t-1}-p\right)\right)}^{\mu_{t}} \varepsilon_{t}
$$

where $\varepsilon_{t}$ is lognormally distributed with mean 1 and variance $\sigma^{2}$. By taking logs (identified with a tilde), the price process can be rewritten as:

$$
\begin{aligned}
& \tilde{p}_{t}=\tilde{\mu}_{t}+\tilde{\varepsilon}_{t} \\
& \tilde{\mu}_{t}=\ln \left(p+\rho\left(p_{t-1}-p\right)\right)
\end{aligned}
$$


so that

$$
\tilde{p}_{t} \mid I_{t-1} \sim N\left(\tilde{\mu}_{t}-\sigma^{2} / 2, \sigma^{2}\right)
$$

where $I_{t-1}$ is the information set at time $t-1$. The likelihood can be written as:

$$
\begin{aligned}
L & =\left(\frac{1}{\sqrt{2 \pi \sigma^{2}}}\right)^{T} \prod_{t=1}^{T} \exp \left(-\frac{1}{2} \frac{\left(\tilde{p}_{t}-\tilde{\mu}_{t}+\sigma^{2} / 2\right)^{2}}{\sigma^{2}}\right) \\
\ln (L) & =-\frac{T}{2} \ln \left(2 \pi \sigma^{2}\right)+\sum_{t=1}^{T}\left(-\frac{1}{2} \frac{\left(\tilde{p}_{t}-\tilde{\mu}_{t}+\sigma^{2} / 2\right)^{2}}{\sigma^{2}}\right)
\end{aligned}
$$

with first order conditions:

$$
\begin{aligned}
\frac{\partial \ln (L)}{\partial p} & =\sum_{t=1}^{T}\left(\frac{(1-\rho)\left(\tilde{p}_{t}-\tilde{\mu}_{t}+\sigma^{2} / 2\right)}{\mu_{t} \sigma^{2}}\right)=0 \\
\frac{\partial \ln (L)}{\partial \rho} & =\sum_{t=1}^{T}\left(\frac{\left(p_{t-1}-\rho\right)\left(\tilde{p}_{t}-\tilde{\mu}_{t}+\sigma^{2} / 2\right)}{\mu_{t} \sigma^{2}}\right)=0 \\
\frac{\partial \ln (L)}{\partial \sigma^{2}} & =-\frac{T}{2 \sigma^{2}}+\sum_{t=1}^{T}\left(-\frac{1}{2} \frac{\left(\tilde{p}_{t}-\tilde{\mu}_{t}+\sigma^{2} / 2\right) \sigma^{2}-\left(\tilde{p}_{t}-\tilde{\mu}_{t}+\sigma^{2} / 2\right)^{2}}{\sigma^{4}}\right) \\
& =\left(-\frac{1}{2 \sigma^{2}}\right)\left(T+\sum_{t=1}^{T}\left(\frac{\left(\tilde{p}_{t}-\tilde{\mu}_{t}+\sigma^{2} / 2\right)\left(\sigma^{2} / 2-\tilde{p}_{t}+\tilde{\mu}_{t}\right)}{\sigma^{2}}\right)\right)=0 .
\end{aligned}
$$

